\title{
Application of the Reactivity Index to Propose Intra and Intermolecular Reactivity in Catalytic Materials
}

\author{
Abhijit Chatterjee \\ Material Science, Accelrys, Nishishinbashi TS Bldg. 11F, 3-3-1 Nishishinbashi, \\ Minato-ku, Tokyo, 105-0003, Japan \\ achatterjee@accelrys.com
}

\begin{abstract}
This study is based on our earlier work with reactivity index to propose intra and inter molecular reactivity in catalytic materials using density functional theory, within the domain of hard soft acid base (HSAB) principle. We have as well shown small example to show directly the utility of this method in elucidating acidity in catalytic material of interest. Our goal is to show that a simple theory can be useful to design new futuristic material of interest.
\end{abstract}

\section{Introduction}

The hard soft acid-base (HSAB) principles classify the interaction between acids and bases in terms of global softness. Pearson proposed the global HSAB principle [1]. The global hardness was defined as the second derivative of energy with respect to the number of electrons at constant temperature and external potential, which includes the nuclear field. The global softness is the inverse of this. Pearson also suggested a principle of maximum hardness $(\mathrm{PMH})$ [2], which states that, for a constant external potential, the system with the maximum global hardness is most stable. In recent days, DFT has gained widespread use in quantum chemistry [3]. This study aims to review the development and application of reactivity index in key catalytic process within our research [4-9].

With this background, the influence of both bivalent and trivalent metal substituents from a range of metal cation $(\mathrm{Co}, \mathrm{Mn}, \mathrm{Mg}, \mathrm{Fe}$ and $\mathrm{Cr}$ ) on the acidic property (both Bronsted and Lewis) of metal substituted aluminum phosphate MeAlPOs is monitored. Intramolecular and intermolecular interactions show that once active site of the interacting species is identified, the influence of the environment can be prescribed.

\section{Theory}

The electronegativity $\chi$, defined by Mulliken as the average of ionization potential I and electron affinity $\mathrm{A}, \chi=1 / 2(\mathrm{I}+\mathrm{A})$, is such a parameter; it is a useful measure of the tendency of a species to attract electrons. Thus the electronegativity $\chi$ has been identified as the negative of the chemical potential $\mu$, which is the Lagrange multiplier in the Euler-Lagrange equation in density functional theory, and

$$
\mu=(\delta \mathrm{E} / \delta \mathrm{N}) v(\mathrm{r})=-\chi
$$


Where, $\mathrm{E}$ is the total electronic energy, $\mathrm{N}$ is the number of electrons, and $\mathrm{v}(\mathrm{r})$ is the external electrostatic potential an electron at $r$ feels due to the nuclei. Mulliken's formula - 1/2(I $+A)$ is no more than the finite-difference approximation for Eq. 1 .

Similarly, the natural definition of the hardness, called $\eta$ has been shown to be

$$
\eta=(\delta 2 \mathrm{E} / \delta \mathrm{N} 2) v(\mathrm{r})=(\mu \delta / \delta \mathrm{N}) v(\mathrm{r})
$$

Which, has the finite-difference approximation I - A. The hardness/softness/acid/base principle has been derived using Eq. 2 as the definition of hardness. On the other hand, the frontier electron densities proposed by Fukui are local properties that depend on r; they differentiate one part of a molecule from another and serve as reactivity indices.

In density functional theory, hardness $(\eta)$ is defined as

$$
\eta=1 / 2\left(\delta^{2} E / \delta N^{2}\right) v(r)=1 / 2(\delta \mu / d N)_{v}
$$

Where $\mathrm{E}$ is the total energy, $\mathrm{N}$ is the number of electrons of the chemical species and the chemical potential.

The global softness, $S$, is defined as the inverse of the global hardness, $\eta$.

$$
\mathrm{S}=1 / 2 \eta=(\delta \mathrm{N} / \delta \mu)_{\mathrm{v}}
$$

Using the finite difference approximation, $\mathrm{S}$ can be approximated as

$$
\mathrm{S}=1 /(\mathrm{IE}-\mathrm{EA})
$$

where IE and EA are the first ionization energy and electron affinity of the molecule, respectively.

The Fukui function $\mathrm{f}(\mathrm{r})$ is defined by

$$
\mathrm{f}(\mathrm{r})=[\delta \mu / \mathrm{dv}(\mathrm{r})]_{\mathrm{N}}=[\delta \rho(\mathrm{r}) / \delta \mathrm{N}]_{\mathrm{v}}
$$

The function ' $\mathrm{f}$ ' is thus a local quantity, which has different values at different points in the species, $\mathrm{N}$ is the total number of electrons, $\mu$ is the chemical potential and $\mathrm{v}$ is the potential acting on an electron due to all nuclei present.

The local softness $\mathrm{s}(\mathrm{r})$ can be defined as

$$
\mathrm{s}(\mathrm{r})=(\delta \rho(\mathrm{r}) / \delta \mu)_{\mathrm{v}}
$$

Equation (9) can also be written as

$$
\mathrm{s}(\mathrm{r})=[\delta \rho(\mathrm{r}) / \delta \mathrm{N}] \mathrm{v}[\delta \mathrm{N} / \delta \mu]_{\mathrm{v}}=\mathrm{f}(\mathrm{r}) \mathrm{S}
$$

Thus, local softness contains the same information as the Fukui function $f(r)$ plus additional information about the total molecular softness, which is related to the global reactivity with respect to a reaction partner, as stated in HSAB principle. Atomic softness values can easily be calculated by using eq 10, namely:

$$
\begin{aligned}
& \mathrm{s}_{\mathrm{x}}{ }^{+}=\left[\mathrm{q}_{\mathrm{x}}(\mathrm{N}+1)-\mathrm{q}_{\mathrm{x}}(\mathrm{N})\right] \mathrm{S} \\
& \mathrm{s}_{\mathrm{x}}{ }^{-}=\left[\mathrm{q}_{\mathrm{x}}(\mathrm{N})-\mathrm{q}_{\mathrm{x}}(\mathrm{N}-1)\right] \mathrm{S} \\
& \mathrm{s}_{\mathrm{x}}{ }^{0}=\mathrm{S}\left[\mathrm{q}_{\mathrm{x}}(\mathrm{N}+1)-\mathrm{q}_{\mathrm{x}}(\mathrm{N}-1)\right] / 2
\end{aligned}
$$

We further explained the interaction energy scheme as follows. This is known that A \& B interacts in two steps: (1) interaction will take place through the equalization of chemical potential at constant external potential and (2) A and B approach the equilibrium state through changes in the electron density of global system generated by making changes in the external potential at constant chemical potential. That means within DFT we can write

$$
\Delta \mathrm{E} \text { inter }=\mathrm{E}[\rho \mathrm{AB}]-\mathrm{E}[\rho \mathrm{A}]-\mathrm{E}[\rho \mathrm{B}]
$$


Where $\rho \mathrm{AB}, \rho \mathrm{A}, \rho \mathrm{B}$ are the electron densities of the systems $\mathrm{AB}$ at equilibrium and of the isolated systems $\mathrm{A}$ and $\mathrm{B}$, respectively

Or in terms of the potentials we can write

$$
\Delta \mathrm{E}_{\text {inter }}=\Delta \mathrm{E}_{\mathrm{v}}+\Delta \mathrm{E}_{\mu}
$$

Where, $\Delta \mathrm{E}_{\mathrm{v}}=-1 / 2\left[\left(\mu_{\mathrm{A}}-\mu_{\mathrm{B}}\right)^{2} /\left(\mathrm{S}_{\mathrm{A}}+\mathrm{S}_{\mathrm{B}}\right)\right]\left(\mathrm{S}_{\mathrm{A}} \mathrm{S}_{\mathrm{B}}\right)$

$$
\Delta \mathrm{E}_{\mu}=-1 / 2 \mathrm{~N}_{\mathrm{AB}}^{2} \mathrm{k}\left[1 /\left(\mathrm{S}_{\mathrm{A}}+\mathrm{S}_{\mathrm{B}}\right)\right.
$$

$\mathrm{N}_{\mathrm{AB}}$ total no. of electrons, $\mathrm{k}$ the proportionality constant between $\mathrm{S}_{\mathrm{AB}}$ and $\mathrm{S}_{\mathrm{A}}+\mathrm{S}_{\mathrm{B}}$, product of $\mathrm{N}^{2}$ and $\mathrm{K}$ is $\lambda$.

$$
\Delta \mathrm{E}_{\mu}=(-1 / 2) \lambda /\left(\mathrm{S}_{\mathrm{A}}+\mathrm{S}_{\mathrm{B}}\right)
$$

If the interaction is taking place through $\mathrm{j}$ site of $\mathrm{A}$,

$$
\lambda_{\mathrm{Aj}}=\mathrm{q}_{\mathrm{Aj}}{ }^{\mathrm{eq}}-\mathrm{q}_{\mathrm{Aj}}{ }^{0}
$$

$\mathrm{q}_{\mathrm{Aj}}{ }^{\mathrm{eq}}$ is density of $\mathrm{jth}$ atom of $\mathrm{A}$ in complex $\mathrm{AB} \& \mathrm{q}_{\mathrm{Aj}}{ }^{0}$ is the density in isolated system.

In our all studies, all calculations with molecular clusters have been carried out with DFT [11] using DMol ${ }^{3}$ code of Accelrys. A gradient corrected functional BLYP [12] and DNP basis set [13] was used through out the calculation. Single point calculations of the clusters in their cationic and anionic form, at the optimized geometry of the original neutral clusters were also carried out to evaluate Fukui functions and global and local softness. The condensed Fukui function and atomic softness were evaluated using eqs 8 and 11, respectively, using electrostatic potential (ESP) driven charges.

\section{Result}

We will now site a short example to show how these calculations can be implemented to design catalytic materials with acidic site activity. Calculations were performed on AlPO34 framework, which is isostructural with zeolite chabazite. The cluster calculations were formed on localized cluster generated from the AlPO34 structure with the terminal $\mathrm{Al}$ or $\mathrm{P}$. Two independent clusters of the formula (1) $\mathrm{M}^{+2} \mathrm{AlP}_{2} \mathrm{O}_{12} \mathrm{H}_{9}$ and (2) $\mathrm{M}^{+3} \mathrm{AlP}_{2} \mathrm{O}_{12} \mathrm{H}_{8}$ generated by replacing one $\mathrm{P}$ by a $\mathrm{M}^{2+}$ or $\mathrm{M}^{3+}$ to represent the bivalent and trivalent dopant incorporated clusters respectively as shown in Figure 1. The proton is included at the bridging oxygen where the dopant is incorporated for electrical neutrality for bivalent substitution. The terminal $\mathrm{Al}$ or $\mathrm{P}$ were replaced by hydrogen at that distance to mimic the real situation. It is observed that for the bivalent dopants the local environment is a distorted tetrahedral. For all the cases the $\mathrm{M}-\mathrm{OH}$ distance is the longest. The M-O distances are considerably longer than the Al-O distance when the AlPO material is undoped, showing that the dopants introduce a considerable amount of distortion in the system. There is a drastic change in the M-O-P and angle values, $\sim 135^{\circ}$ compared to the Al-O-P $\sim 148^{\circ}$, which show that the observed structural distortion is not local and can be propagated beyond the nearest neighbor to the undoped region, which is in sharp contrast to the earlier results of Saadoune et al [14].

To correlate the activity of dopants, hence we performed localized reactivity index calculation for the bivalent dopants using $\mathrm{M}^{+2} \mathrm{AlP}_{2} \mathrm{O}_{12} \mathrm{H}_{9}$ cluster. The Fukui function and local softness for the hydroxyl proton is presented both in terms of nucleophilic and electrophilic activity. Relative electrophilicity $\left(\mathrm{s}_{\mathrm{x}}{ }^{+} / \mathrm{s}_{\mathrm{x}}{ }^{-}\right)$and relative nucleophilicity 




(a) Bivalent

b) Trivalent

Fig. 1. Two independent cluster with the formula (a) $\mathrm{M}^{+2} \mathrm{AlP}_{2} \mathrm{O}_{12} \mathrm{H}_{9}$ and (b) $\mathrm{M}^{+3} \mathrm{AlP}_{2} \mathrm{O}_{12} \mathrm{H}_{8}$ to represent the bivalent and trivalent dopant incorporated clusters. Color code is as follows: red oxygen, black phosphorous, light pink aluminum, light blue is the bivalent, deep blue is trivalent metal cation, white is the hydrogen.

Table 1. Local softness and relative nucleophilicity for the bivalent dopants calculated in terms of the hydroxyl proton using ESP charges by DFT to monitor Bronsted acidity trend

\begin{tabular}{|r|r|r|r|}
\hline $\begin{array}{c}\text { Metal } \\
\text { ion }\end{array}$ & $\mathrm{s}_{\mathrm{x}}{ }^{+}$ & $\mathrm{s}_{\mathrm{x}}{ }^{-}$ & $\begin{array}{c}\mathrm{s}_{\mathrm{x}}{ }^{+} / \\
\mathrm{Mg}^{-}{ }^{2+}\end{array}$ \\
\hline $\mathrm{Mn}^{2+}$ & 0.20 & 0.53 & 2.555 \\
\hline $\mathrm{Cr}^{2+}$ & 0.37 & 0.32 & 1.156 \\
\hline $\mathrm{Co}^{2+}$ & 0.43 & 0.44 & 0.977 \\
\hline $\mathrm{Fe}^{2+}$ & 0.53 & 0.36 & 1.478 \\
\hline & 0.53 & 0.44 & 1.204 \\
\hline
\end{tabular}

$\left(\mathrm{s}_{\mathrm{x}}{ }^{-} / \mathrm{s}_{\mathrm{x}}{ }^{+}\right)$can be defined as the electrophilicity of any site as compared to its own nucleophilicity for the first term and vice versa. Table 1. Local softness and relative nucleophilicity for the bivalent and trivalent dopants calculated in terms of the dopant using ESP charges by DFT to monitor Lewis acidity trend.

The relative nucleophilicity is highest for $\mathrm{Mg}^{2+}$ and is lowest for $\mathrm{Cr}^{2+}$, which is opposite to the trend observed in terms of substitution energy. Fukui functions were used to monitor the dopants activity in terms of Lewis acidity. The results are shown in Table 2. For bivalent cation this order is totally different form the order obtained in terms of substitution energy and that obtained from the Bronsted acidity trend. For the trivalent dopant the highest nucleophilicity lies with $\mathrm{Fe}^{3+}$ and the lowest is for $\mathrm{Mn}^{3+}$; the results matches with the trend of substitution energy. The trend for Bronsted acidity is $\mathrm{Cr}^{2+}<\mathrm{Mn}^{2+}<\mathrm{Fe}^{2+}<\mathrm{Co}^{2+}<\mathrm{Mg}^{2+}$, where as the trend for Lewis acidity mainly for trivalent metal dopant is $\mathrm{Fe}^{3+}>\mathrm{Co}^{3+}>\mathrm{Cr}^{3+}>\mathrm{Mn}^{3+}$. This optimistic result encourages us to monitor a mixed valence situation, which may ideally exist during calcinations for the cations with variable oxidation state. 


\section{Conclusion}

The current work with all our previous work described here is aimed to resolve the issues within the domain of catalysis, we are now capable of using reactivity index to design new catalytic material of interest. The theory derived has ample application in analytical chemistry, industrial chemistry, organic chemistry and all. This is simple tool based on basic theory of donor and acceptor behavior with a great impact to resolve correlated issues.

\section{Reference}

1. Pearson, R. G. Recent advances in the concept of hard and soft acids and bases. J. Chem. Edu. 64 (1987) 561-567.

2. Parr, R. G., and Pearson, R. G. Absolute hardness - companion parameter to absolute electronegativity. J. Am. Chem. Soc. 105 (1983) 7512-7516.

3. Geerlings, P., and De Proft, F. HSAB principle: Applications of its global and local forms in organic chemistry. Int. J. Quant. Chem. 80 (2000) 227-235.

4. Chatterjee, A., Iwasaki, T., and Ebina, T. Reactivity index scale for interaction of heteroatomic molecules with zeolite framework. J. Phys. Chem. A. 103 (1999) 2489-2494.

5. Chatterjee, A. and Iwasaki, T. A Reactivity Index Study to Choose the Best Template for a Particular Zeolite Synthesis, J. Phys. Chem. A 105 (2001) 6187-6196.

6. Chatterjee, A., Iwasaki, T. and Ebina, T. Best dioctahedral smectite for nitrogen heterocyclics adsorption - a reactivity index study, J. Phys. Chem. A 105 (2001) 10694-10701.

7. Chatterjee, A., Ebina, T., Iwasaki, T. and Mizukami, F. Intermolecular Reactivity Study to Scale Adsorption Property of Para and Meta Substituted Nitrobenzene over 2:1 Dioctahedral Smectite J. Chem. Phys. 118 (2003) 10212-10220.

8. Chatterjee, A., Ebina, T., Onodera, Y. and Mizukami, F. 2,3,7,8 tetrachloro Dibenzo-p-dioxin Can Be Successfully Decomposed over 2:1 Dioctahedral Smectite - A Reactivity Index Study, J. Mol. Graphics \& Modeling 22 (2003) 93-104.

9. Chatterjee, A., Suzuki, T.; Takahashi, Y.; Tanaka, D.A.P. A density functional study to choose the best fluorophore for PET sensor Chemistry - A European Journal 9 (2003) 3920-3929.

10. Chatterjee, A., Ebina, T., Onodera, Y. and Mizukami, F. Effect of exchangeable cation on the swelling property of 2:1 dioctahedral smectite - a periodic first principle study, J. Chem. Phys. 120 (2004) 3414-3424.

11. Delley, B., An all-electron numerical-method for solving the local density functional for polyatomic-molecules. J. Chem. Phys. 92 (1990) 508-517.

12. Becke, A. D., A multicenter numerical-integration scheme for polyatomic-molecules. J. Chem. Phys. 88 (1988) 2547-2553.

13. Lee, C. T., Yang, W. T., and Parr, R. G. Development of the Colle-Salvetti correlation-energy formula into a functional of the electron-density. Physical Review B. 37 (1988) 785-789.

14. Saadoune, I.; Catlow, C.R.A.; Corà, F. Site ordering of dopant ions in microporous aluminophosphates-size effects Microporous and Mesoporous Materials, 59 (2003) 161-165. 